Article

\title{
Decision Making of Non-Agricultural Work by Rural Residents in Weifang, China
}

\author{
Yang Cheng ${ }^{1}$ (D), Yuxia Lv $^{2,3}$, Mark Rosenberg ${ }^{4}$ and Linke Hou ${ }^{3, *(1)}$ \\ 1 Faculty of Geographical Science, Beijing Normal University, Beijing 100875, China; chengyang@bnu.edu.cn \\ 2 Emerging Economic Formats Research Institute, Shandong Management University, Ji'nan 250100, \\ Shangdong, China; yuxialv@126.com \\ 3 Center for Economic Research, Shandong University, Ji'nan 250100, Shangdong, China \\ 4 Department of Geography and Planning, Queen's University, Kingston, ON K7L 3N6, Canada; \\ mark.rosenberg@queensu.ca \\ * Correspondence: abramhlk@sdu.edu.cn
}

Received: 15 April 2018; Accepted: 16 May 2018; Published: 20 May 2018

\begin{abstract}
Since the 1990s, the rapid urbanization of China has been fueled by the massive movement of workers from the countryside to cities. Using descriptive statistics and binary regression analysis, we investigate the factors underlying rural residents' decision making to seek non-agricultural work, their work time, and work location based on data collected in Weifang, a city in the Shandong Province of China. The results show that economic factors play a pivotal role in rural residents' decision making to seek non-agricultural employment, full-time non-agricultural employment, or employment outside of their home county. Non-economic factors such as age, gender, social ties, education, access to arable land, geographical location, neighborhood effects, and self-perception are also significant factors in the decision-making process. The findings of this study shed light on future research regarding the impact of urbanization on rural residents. It also provides knowledge for future policy making on rural development and management.
\end{abstract}

Keywords: non-agricultural work; work location; rural residents; China

\section{Introduction}

The pace of urbanization in China from the foundation of China in 1949 to 1980s was relatively slow because of the rapid growth of the rural population and tight restrictions on rural-urban migration. Since the 1990s, the rapid urbanization of China has been fueled by the massive movement of the labor force from the countryside to the cities after the development in the east and south coastal regions of China [1]. Census data show that about 260 million Chinese people were living away from where they were formally registered, and about 220 million were rural migrants working in urban areas with rural household registration in 2010 [2]. The flows of rural-to-urban migration include migrants who move from rural areas to nearby cities (relatively short distance moves) and those who moved from undeveloped rural hinterlands into modern mega cities (long distance moves). In addition, there is a unique pattern of seasonal migrants who move back and forth to nearby urban areas from their village of origin.

Many researchers are interested in understanding the underlying factors motivating the various types of population migration. The push-pull model is one of the most popular models used for understanding both economic and non-economic factors to explain people's migration behavior. From an economic perspective, migration is the result of a complex decision-making process taking into account the costs and benefits of movement to maximize earnings [3,4]. Those who are best able to capitalize on such migration (for example, the young, the well-educated, and the skilled) are thought 
to be the most likely to move. Massey et al. viewed migration as a household strategy, not just an individual decision, based on the financial benefits from migration [5]. Migrants usually make money in the urban areas and often send remittances back to their origin household [6,7]. Once their financial needs are met, they may return to their origins and resume their usual farming or other work activities, even starting a small business [8,9].

Since the late 1990s, there has been a growing awareness of the role of non-economic factors in migration, including social networks, kinship groups, and organizations $[5,10,11]$. The concept of 'social embeddedness' was developed to study the migration decision, which referred to social relations fostering a sense of belonging and integration in the local surroundings [12,13]. Piotrowski and Tong extended the idea to an understanding of the influence of social networks, social relations, and community structures at both the origin and destination [9]. Factors such as moving with a spouse and other family members, having co-workers from their origin village, living in a neighborhood with fellow migrants increase the embeddedness of the migrants in the destination. The pull force of social ties to family, friends, and acquaintances at the origin can also exert a strong influence on any intentions to return to their place of origin. For example, factors such as marital status, having children who are left behind, and obligations to aging parents can strongly motivate migrants to return to their places of origin.

Previous empirical studies on the determinants of migration in the Chinese context have found that young, single adults without dependents are more likely to migrate; men migrate more frequently than women; and those with more agricultural land are less likely to migrate [1,14-18]. However, Li and Zahniser found that the probability of migration increases with age until the age of 27 and then declines [19].

With regard to the impact of children and the elderly, Li and Zahniser found that females were less likely to migrate as the number of pre-school children in the household increased [19]. Due to a lack of social security provisions in rural areas, ill health of elderly parents reduced the probability of migration for adult children [20]. Mullan and Grosjean drew a distinction between agricultural and forestry worker households [21]. They found that the number of children in a household had a negative effect on the numbers of migrants, both in agricultural and forestry worker households, while the number of elderly members only had negative impacts on forestry worker households. Both males and females became more likely to migrate as the household size increased.

The impact of education shows that the least-educated and most-educated members of rural communities were less likely to migrate, which was demonstrated in a study conducted by Zhao [18]. However, Hare found that years of formal education did not appear to have an important effect on the probability of migrating [14].

Regarding financial factors, Li and Zahniser found that an increase in the farming income reduced the probability of migration [19]. The amount of land controlled by the household did not have a significant effect on migration in most provinces. Mullan and Grosjean found that the area of agricultural land was negatively related to the number of household members migrating, although the area of forest land did not have a significant effect [21]. Rozelle et al. found that farmers from poor villages were more likely to migrate, and the ability to rent land had positive impacts on migration [16].

In terms of the spatial interaction between origins and destinations, gravity models have been applied to model migration streams [22,23]. In order to improve the model for taking into account the spatial configuration of origins and destinations, some researchers such as Borgers and Timmermans have created new models, and some others have improved existing models considering the spatial structural effects [24-26]. Boots and Kanaroglou developed a measure of spatial structure to be incorporated into the nested logit model [27]. However, data on both the origins and destinations and the distance between them are usually required for spatial analysis. Logistic regression models are commonly applied for understanding the influencing factors on migration and relocation [28,29]. In this study, the distance factor is taken into account via the variable "village location" by applying 
the logistic regression model instead of the data-intensive gravity model, considering the availability of the data.

The setting for our study is Weifang, a city located in central Shandong Province. In terms of the total Gross Domestic Product (GDP), the Shangdong Province ranks third among all the provinces in China in 2010. Weifang includes four districts and six counties and it is the second largest city in Shangdong with a population of 9.1 million in 2010. Weifang has witnessed the rapid economic growth over the past 30 years with an average annual growth rate above nine percent per year. Rapid economic development and industrialization created huge demands to expand the labor force resulting in the transfer of rural workers from the agricultural sector to the urban industrial and service sectors, distinct from rural migrants from the inland provinces in China who migrate long distances to find urban employment in coastal provinces. The farmers in Weifang provide a case study of migrants in the relatively developed regions in East China. Meanwhile, the Shandong Province is the origin of the Confucius Culture in ancient China. The culture of filial piety still plays an important role in families' support on elder care. It is significant to understand if the traditional culture has an impact on people's intention for migration in the context of rapid urbanization in China.

Existing studies suggest that both economic and non-economic factors are important to the decision of migration. How the economic and non-economic factors affect the type of employment, the length of time working in urban areas and the work locations, however, have not been fully studied in the context of the rapid urbanization in China. To understand this question, it is beneficial for the sustainable development of both the origin and destination of migration.

In this study, we want to test the following six hypotheses. First, rural residents who are young, male, and single are more likely to migrate and conduct full-time non-agricultural work out of their county.

Second, the number of the elderly and children in the household has a negative impact on the likelihood to migrate and conduct full-time non-agricultural work out of the county.

Third, rural residents with better education, higher annual income per capita, land requisitioned, and own property in the city are more likely to migrate and conduct full-time non-agricultural work out of the county.

Fourth, the annual agricultural income per capita, average arable land per capita, being a party member and a village official have a negative impact on the likelihood to migrate and conduct full-time non-agricultural work out of the county.

Fifth, rural residents who live in a village located next to an urban area and where the average percentage of farmers conducting non-agricultural activity in the village is high are more likely to be full-time non-agricultural workers out of the county.

Sixth, rural residents who have a high life satisfaction, a positive evaluation of the effect of local urbanization, and assume a high likelihood of finding non-agricultural work are more likely to be full-time non-agricultural workers out of the county.

By testing these hypotheses, we aim to understand what factors underlie rural residents' choices between agricultural and non-agricultural work, the length of time rural residents work in urban areas, and the choice of a workplace for non-agricultural work among rural residents in Weifang, which has not been well studied.

The following section explains the process of data collection and the methods of statistical analysis. The results are presented in the third section. Conclusions are drawn and discussed in the last section.

\section{Data and Methods}

\subsection{Data Collection}

The data for this study were collected by a questionnaire survey as part of a larger project to understand rural residents' willingness to urbanize, agricultural and non-agricultural activities, and population migration in Weifang of Shandong Province. 
Probability Proportional to Size (PPS) sampling was used to select sampled counties (districts), villages, and towns. Among the four districts and six counties in Weifang, two districts and four counties were randomly selected for the survey (Figure 1). They are the Weicheng district, the Hanting district, Zhucheng city (county-level), Shouguang city (county-level), Gaomi county, and Linqu county. Two townships were randomly selected in each county (district) with one located next to urban areas and the other located in some distance away from the urban area. One village was selected in each sampled township that is next to urban areas and two villages were selected in each sampled township that is not adjacent to urban areas. The village households were randomly sampled based on the roster of the village households. Twenty households were interviewed in each village. Following this strategy, there were six sampled counties (districts), 12 sampled townships, 16 villages, and 320 households selected in total. Only those cases without missing data were included in the final analysis. This resulted in a sample size of 316 households with 606 workers aged between 18 and 60 for the following analysis.

\section{The Location of the Sample Sites}

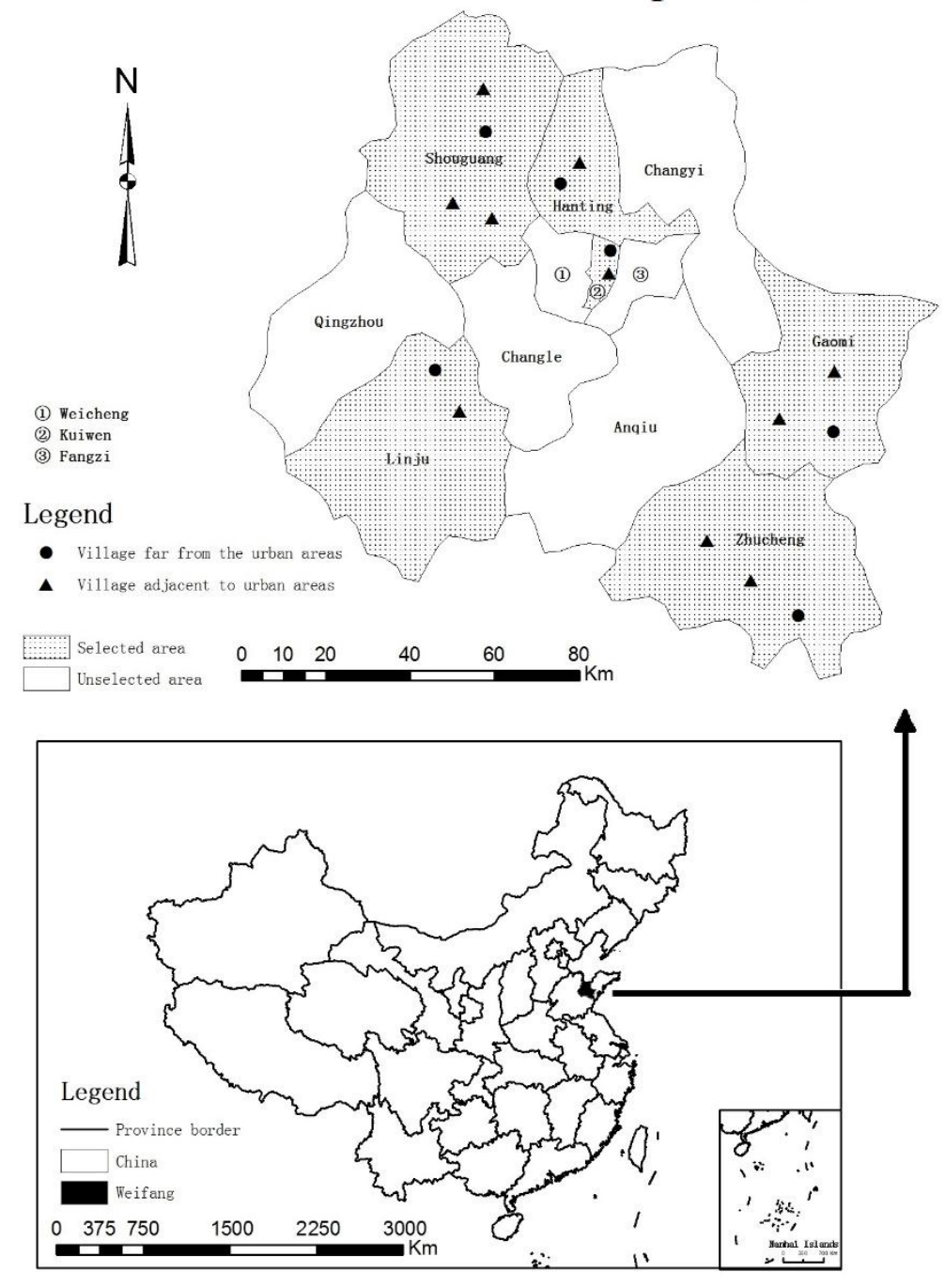

Figure 1. The location of the sample sites.

The data collection was conducted in June and July of 2013. Research assistants were trained to interview rural residents before they went into the field. The interviewers were directed to the prospective participants and briefly outlined the study using a recruitment script and invited the residents to participate in the study. Following informed oral consent, the interviewers asked questions 
on the designed questionnaires and filled in the questionnaires based on the interviewee's answers, which took an average of $40 \mathrm{~min}$ to complete. Ethics approval for the research project was obtained from Shandong University in China.

\subsection{Statistical Analysis}

Descriptive statistics are used to summarize the characteristics of the rural labor force in the study sample. To estimate the unadjusted association between working activities and demographic and socio-economic factors, descriptive statistics (percentages) and $t$-tests were conducted. A binary logistic regression analysis was performed in three models to determine the adjusted associations between the dependent variables and the independent variables.

We selected variables that affect the decision to seek non-agricultural work, the length of time and work locations based on the demographic characteristics, socio-economic characteristics, land and agriculture factors, neighborhood effects, and subjective evaluation of the respondents. Demographic characteristics included age, gender, marital status, number of the elderly aged 65 and over in the household, and number of children under seven in the household. Socio-economic characteristics included education level, annual income per capita, party membership, having a village official in the household (now or in the past), and owning property in the city. Land and agriculture factors included average arable land per capita, land being requisitioned, and annual agricultural income per capita. Neighborhood effects included whether a worker lived in a village next to an urban area and the average percentage of farmers conducting non-agricultural activity in the village. Subjective evaluation included life satisfaction, evaluation of local urbanization in the county or district, and evaluation of the likelihood of finding non-agricultural work.

Whether rural residents conduct non-agricultural work (the farmer did non-agricultural work in the past 12 months = 1 ; the farmer did not do non-agricultural work in the past 12 months $=0$ ), whether they participate in full-time non-agricultural work (the farmer did full-time non-agricultural work in the past 12 months = 1; the farmer took part-time non-agricultural work or agricultural work in the past 12 months $=0$ ), and the work location (the farmer took non-agricultural work outside of home counties over three months $=1$, the farmer worked in their home counties $=0$ ) were the binary variables used as the dependent variables in the three logistic regression models, respectively.

Table 1 presents the definitions and descriptions of each variable. The results from the logistic regression analysis were presented as odds ratios with 95 percent confidence intervals. All analyses were conducted using STATA Version 12 with a level of statistical significance set at $p \leq 0.05$. 
Table 1. The description of variables.

\begin{tabular}{|c|c|c|}
\hline Variable & Data Type & Description \\
\hline \multicolumn{3}{|l|}{ Dependent variables } \\
\hline Non-agricultural Work & Binary & An indicator of non-agricultural work in the past 12 month $(1=$ Yes; $0=$ No $)$ \\
\hline Full-Time Non-agricultural Work & Binary & An indicator of full-time non-agricultural work in the past 12 month $(1=$ Yes; $0=\mathrm{No})$ \\
\hline Work Location & Binary & $\begin{array}{l}\text { An indicator of whether or not the farmer took non-agricultural work away from her/his county over three } \\
\text { months }(1=\text { Yes; } 0=\mathrm{No})\end{array}$ \\
\hline \multicolumn{3}{|l|}{ Independent variables } \\
\hline \multicolumn{3}{|l|}{ Demographic Characteristics } \\
\hline Age & Continuous & Age (Year) \\
\hline Gender & Binary & Gender (1 = Male; $0=$ Female $)$ \\
\hline Spouse & Binary & An indicator of whether the person has a spouse or not $(1=\mathrm{Yes} ; 0=\mathrm{No})$ \\
\hline Number of the elderly aged 65 and over & Continuous & Numbers of the elderly aged 65 and over in the household \\
\hline Number of child under 7 & Continuous & Numbers of children under seven in the household \\
\hline \multicolumn{3}{|l|}{ Socio-Economic Characteristics } \\
\hline Education & Continuous & Years of formal education (Year) \\
\hline Annual income per capita (in logarithm) & Continuous & Annual average income per capita in the household (1000 Yuan) in logarithm \\
\hline Party member & Binary & An indicator of party member $(1=$ Yes; $0=\mathrm{No})$ \\
\hline Whether being a village official & Binary & An indicator of whether or not any family member has served as a village official ( $1=$ Yes; $0=\mathrm{No}$ ) \\
\hline Whether own property in city & Binary & An indicator of whether or not family own a house in city $(1=$ Yes; $0=$ No $)$ \\
\hline \multicolumn{3}{|l|}{ Land and Agriculture } \\
\hline Average arable land per capita & Continuous & Average arable land within family $(\mathrm{Mu})$ \\
\hline Family with land requisitioned & Binary & An indicator of whether or not land has been requisitioned by the government $(1=$ Yes; $0=\mathrm{No})$ \\
\hline Annual agricultural income per capita (in logarithm) & Continuous & Annual average income from agricultural activity in the household (1000 Yuan) in logarithm \\
\hline \multicolumn{3}{|l|}{ Neighborhood effects } \\
\hline Village location & Binary & An indicator of whether the village is next to the urban area $(1=$ Yes; $0=$ No) \\
\hline Percentage of residents conducting non-agricultural work & Continuous & Average percentage of farmers with non-agricultural work in the village (excluding the respondent family) \\
\hline \multicolumn{3}{|l|}{ Subjective Evaluation } \\
\hline Life satisfaction & Category & Five scales where one denotes the least satisfaction and five denotes the most satisfaction. \\
\hline Evaluation of local urbanization & Category & Five scales where one denotes the least satisfaction and five denotes the most satisfaction. \\
\hline Evaluation of non-agricultural work finding & Category & Five scales where one denotes the least satisfaction and five denotes the most satisfaction. \\
\hline
\end{tabular}




\section{Results}

A total of 320 households were interviewed and 316 questionnaires were collected without missing information for this research. The completion rate was 98.8 percent (that is, questionnaires with no missing data divided by the total number of questionnaires completed). We collected the job choice information of every family member in each household. In total, 1133 persons in 316 households were surveyed and 606 samples, from persons aged between 18 and 60, were included in this study for the analysis of their non-agricultural work choice.

Table 2 summarizes the characteristics of the participants overall, by their types of work activities. The average age of the study sample was 42.8 (SD: 11.4) years. The average age of non-agricultural workers was 15.3 years younger than that of the agricultural workers $(33.0$ vs. $48.3, p<0.001)$. Non-agricultural workers were less likely to have spouses $(58.8 \%$ vs. $95.1 \%, p<0.001)$ but more likely to have children under seven $(33.8 \%$ vs. $23.6 \%, p=0.01$ ), have a better education (years of formal education 11.2 vs. $7.6, p<0.001)$, have a higher annual incomes per capita $(37,800$ vs. $17,900 \mathrm{RMB}$, $p<0.001)$, less likely to have family members who are village officials $(3.7 \%$ vs. $12.6 \%, p<0.001)$, more likely to own property in the city $(35.7 \%$ vs. $15.6 \%, p<0.001)$, have less arable land per capita ( 0.9 vs. $1.5 \mathrm{Mu}, p<0.001)$, more likely to have land requisitioned $(40.7 \%$ vs. $21.0 \%, p<0.001)$, have less agricultural income per capita (3,300 vs. 5,100 RMB, $p=0.03)$, more likely to live in villages next to urban areas $(43.1 \%$ vs. $29.2 \%, p<0.001)$, more likely to live in villages with a higher percentage of residents conducting non-agricultural work ( $57.6 \%$ vs. $49.6 \%, p<0.001)$, and more likely to have positive evaluations of urbanization $(96.8 \%$ vs. $91.3 \%, p=0.01)$ and non-agricultural work opportunities $(88.0 \%$ vs. $77.7 \%, p<0.001)$ than agricultural workers.

To check workers' stability of activity across the years, we also collected information about what type of job (non-agriculture or agriculture) they took in 2012 and 2013 and calculated the transitional probability of job choice from 2012 to 2013 . Agricultural workers' job choices remained considerably stable across years. Of 329 farmers who took non-agricultural jobs in 2012, only three persons (roughly $0.9 \%$ ) quit their non-agricultural jobs in 2013 and only 17 of 277 agricultural farmers (roughly 6\%) in 2012 moved to the non-agricultural sector in 2013.

The age structure of the labor force in the rural areas of Weifang is presented in Figure 2. The distributions of the two groups of farmers, non-agricultural and agricultural, are clearly different from each other. The former is skewed largely toward the left side and the latter towards the right side. From the contrasting skewness of the distributions, it can be inferred that most of the younger, high-quality rural labor force are attracted to non-farming sectors, while older farmers are left behind and have no choice but to take less profitable agricultural jobs. The result aligns with other research, which finds that China witnessed an accelerating trend of aging in the agricultural labor force and its consequential loss of efficiency [30].

The results of the test for multicollinearity of all the variables resulted in VIF scores ranging from 1.09 to 2.34 , which fall far below the rule of thumb threshold of 10 , indicating little concern about multicollinearity. The results of the binary logistic regression are presented in Table 3. 
Table 2. Sample characteristics of non-agricultural and agricultural workers aged between 18 and $60(n=606)$.

\begin{tabular}{|c|c|c|c|c|c|}
\hline Variable & Non-Agricultural Activity (A) & Agricultural Activity (B) & Total & Difference (B-A) & $p$-Value \\
\hline \multicolumn{6}{|l|}{ Demographic Characteristics } \\
\hline Age (Year) & 33.0 & 48.3 & 42.8 & $15.3^{* * *}$ & 0.00 \\
\hline Male (\%) & 55.6 & 48.7 & 51.2 & -6.9 & 0.11 \\
\hline Spouse $(\%)$ & 58.8 & 95.1 & 82.2 & $36.3^{* * *}$ & 0.00 \\
\hline Family with child less than $7(\%)$ & 33.8 & 23.6 & 27.2 & $-10.2 * *$ & 0.01 \\
\hline \multicolumn{6}{|l|}{ Socio-Economic Characteristics } \\
\hline Education (Year) & 11.2 & 7.6 & 8.9 & $-3.6^{* * *}$ & 0.00 \\
\hline Annual income per capita (1000 Yuan) & 37.8 & 17.9 & 25.0 & $-19.9^{* * *}$ & 0.00 \\
\hline Village official (\%) & 3.7 & 12.6 & 9.4 & $8.9^{* * *}$ & 0.00 \\
\hline Own property in city $(\%)$ & 35.7 & 15.6 & 22.8 & $-20.1^{* * *}$ & 0.00 \\
\hline \multicolumn{6}{|l|}{ Land and Agriculture } \\
\hline Average arable land per capita $(\mathrm{Mu})^{1}$ & 0.9 & 1.5 & 1.3 & $0.6^{* * *}$ & 0.00 \\
\hline Family with land requisitioned (\%) & 40.7 & 21.0 & 28.1 & $-19.7^{* * *}$ & 0.00 \\
\hline Annual agricultural income per capita (1000 Yuan) & 3.3 & 5.1 & 4.5 & $1.8^{*}$ & 0.03 \\
\hline \multicolumn{6}{|l|}{ Neighborhood Effect } \\
\hline Village location close to city (\%) & 43.1 & 29.2 & 34.2 & $-13.9 * * *$ & 0.00 \\
\hline Percentage of residents conducting non-agricultural job (\%) & 57.6 & 49.6 & 52.5 & $-8.0 * * *$ & 0.00 \\
\hline Life satisfaction $(\%)$ & 85.2 & 81.0 & 82.5 & -4.2 & 0.20 \\
\hline Evaluation of local urbanization (\%) & 96.8 & 91.3 & 93.2 & $-5.5^{*}$ & 0.01 \\
\hline Evaluation of non-agricultural job finding (\%) & 88.0 & 77.7 & 81.4 & $-10.3^{* *}$ & 0.00 \\
\hline Sample & 606 & & & & \\
\hline
\end{tabular}

Note: * refers to $p \leq 0.05,{ }^{* *}$ refers to $p \leq 0.01 ; * * *$ refers to $p \leq 0.001 .{ }^{1}$. One hectare equals $15 \mathrm{Mu} .{ }^{2}$. Scale 1 and 2 are categorized as not satisfied and scale 3 to 5 are categorized as satisfied. 
Table 3. The binary logistic regression model results on non-agricultural jobs and the associations with personal and neighborhood characteristics $(N=606)$.

\begin{tabular}{|c|c|c|c|c|c|c|c|c|c|}
\hline \multirow{3}{*}{ Variable } & \multicolumn{3}{|c|}{ Model 1} & \multicolumn{3}{|c|}{ Model 2} & \multicolumn{3}{|c|}{ Model 3} \\
\hline & \multicolumn{3}{|c|}{ Non-Agricultural Job } & \multicolumn{3}{|c|}{ Full-Time Non-Agricultural Job } & \multicolumn{3}{|c|}{ Work Location } \\
\hline & OR & $p$ Value & $95 \% \mathrm{CI}$ & OR & $p$ Value & $95 \% \mathrm{CI}$ & OR & $p$ Value & $95 \% \mathrm{CI}$ \\
\hline \multicolumn{10}{|l|}{ Demographic Characteristics } \\
\hline Age (Year) & $0.87^{* * *}$ & 0.00 & $(-0.19-0.06)$ & 0.98 & 0.61 & $(-0.10-0.06)$ & $0.94^{* * *}$ & 0.00 & $(-0.09--0.03)$ \\
\hline Gender $(1=$ Male; $0=$ Female $)$ & 1.00 & 0.84 & $(-0.01-0.01)$ & 1.00 & 0.90 & $(-0.01-0.01)$ & $1.01^{* * *}$ & 0.00 & $(0.01-0.02)$ \\
\hline Spouse $(1=$ Yes; $0=\mathrm{No})$ & $0.97^{* * *}$ & 0.00 & $(-0.04-0.01)$ & 0.99 & 0.34 & $(-0.04-0.01)$ & $0.99 * * *$ & 0.00 & $(-0.01--0.00)$ \\
\hline Number of the elderly aged 65 and over & 0.99 & 0.98 & $(-0.98-0.96)$ & 1.70 & 0.29 & $(-0.76-2.57)$ & $0.83 *$ & 0.09 & $(-0.24-0.11)$ \\
\hline Number of child under 7 & 1.01 & 0.25 & $(-0.00-0.02)$ & $1.01 * *$ & 0.05 & $(0.00-0.03)$ & 1.00 & 0.43 & $(-0.01-0.02)$ \\
\hline \multicolumn{10}{|l|}{ Socio-Economic Characteristics } \\
\hline Education (Year) & $1.25^{* * *}$ & 0.00 & $(0.14-0.42)$ & $1.13^{*}$ & 0.10 & $(-0.02-0.30)$ & $1.10 * *$ & 0.01 & $(0.03-0.19)$ \\
\hline Annual income per capita (in logarithm, 1000 Yuan) & $3.34 * * *$ & 0.00 & $(3.37-4.69)$ & $3.50 * *$ & 0.01 & $(1.17-7.59)$ & $4.63^{* * *}$ & 0.00 & $(4.78-9.40)$ \\
\hline Party membership $(1=$ Yes; $0=$ No $)$ & 1.00 & 0.80 & $(-0.01-0.01)$ & 1.00 & 0.59 & $(-0.01-0.02)$ & 1.01 & 0.34 & $(-0.01-0.02)$ \\
\hline Village official $(1=$ Yes; $0=\mathrm{No})$ & 0.99 & 0.38 & $(-0.04-0.01)$ & $1.02 * *$ & 0.04 & $(0.00-0.04)$ & 0.99 & 0.14 & $(-0.03-0.00)$ \\
\hline Own property in city $(1=$ Yes; $0=$ No $)$ & $1.01 *$ & 0.08 & $(-0.01-0.01)$ & 1.01 & 0.28 & $(-0.01-0.02)$ & $1.02^{* * *}$ & 0.00 & $(0.01-0.03)$ \\
\hline \multicolumn{10}{|l|}{ Land and agriculture } \\
\hline Average arable land per capita $(\mathrm{Mu})$ & $0.52^{* * *}$ & 0.01 & $(-0.62--0.11)$ & 1.05 & 0.94 & $(-1.24-1.33)$ & 0.90 & 0.62 & $(-0.46-0.28)$ \\
\hline Family with land requisitioned $(1=$ Yes; $0=\mathrm{No})$ & 1.02 & 0.26 & $(-0.00-0.03)$ & $0.98 * * *$ & 0.00 & $(-0.03-0.01)$ & 1.00 & 0.57 & $(-0.00-0.01)$ \\
\hline Annual agricultural income per capita (in logarithm, 1000 Yuan) & $0.98^{*}$ & 0.09 & $(-0.54-0.49)$ & 1.04 & 0.90 & $(-0.60-0.69)$ & $0.63 * *$ & 0.02 & $(-0.52--0.05)$ \\
\hline \multicolumn{10}{|l|}{ Neighborhood Effect } \\
\hline Village location ( 1 = Next to city; 0 = Else $)$ & 0.95 & 0.21 & $(-0.08--0.01)$ & $1.15^{* * *}$ & 0.00 & $(0.14-0.18)$ & 0.99 & 0.24 & $(-0.02-0.01)$ \\
\hline Percentage of residents conducting non-agricultural job (\%) & $1.09 * * *$ & 0.00 & $(0.04-0.15)$ & 1.02 & 0.63 & $(-0.05-0.08)$ & 1.05 & 0.14 & $(-0.02-0.11)$ \\
\hline \multicolumn{10}{|l|}{ Subjective Assessment ${ }^{1}$} \\
\hline Life satisfaction (Scale 5) & 0.31 & 0.81 & $(-3.29-2.56)$ & 4.13 & 0.31 & $(-5.45-17.19)$ & 1.23 & 0.56 & $(2.10-3.35)$ \\
\hline (Scale 4) & 0.42 & 0.86 & $(-4.34-3.61)$ & 5.06 & 0.18 & $(-3.92-20.32)$ & 2.9 & 0.43 & $(2.76-3.30)$ \\
\hline (Scale 3) & 0.65 & 0.93 & $(-6.23-5.67)$ & 1.4 & 0.22 & $(4.83-57.62)$ & 1.23 & 0.54 & $(1.49-2.19)$ \\
\hline Evaluation of local urbanization (Scale 5) & 1.08 & 0.52 & $(6.98-11.68)$ & 1.08 & 0.23 & $(1.48-2.73)$ & $1.04^{* * *}$ & 0.00 & $(-0.19-0.05)$ \\
\hline (Scale 4) & 1.05 & 0.34 & $(8.75-15.71)$ & 0.98 & 0.18 & $(1.15-4.78)$ & $1.07^{* * *}$ & 0.00 & $(-0.31--0.06)$ \\
\hline (Scale 3) & 1.09 & 0.29 & $(7.91-12.16)$ & 1.18 & 0.33 & $(1.03-2.08)$ & $1.03^{* * *}$ & 0.01 & $(-0.48--0.05)$ \\
\hline Evaluation of non-agricultural job finding (Scale 5) & $5.55 * *$ & 0.04 & $(0.67-18.35)$ & 0.77 & 0.86 & $(-2.44-2.04)$ & 1.60 & 0.45 & $(-1.18-2.68)$ \\
\hline (Scale 4) & 2.05 & 0.41 & $(-2.06-5.00)$ & 2.52 & 0.44 & $(-3.62-8.29)$ & 0.84 & 0.81 & $(-1.39-1.09)$ \\
\hline (Scale 3) & 0.75 & 0.83 & $(-2.20-1.77)$ & 2.81 & 0.42 & $(-4.22-10.03)$ & 0.62 & 0.57 & $(-1.31-0.71)$ \\
\hline (Scale 2) & 0.74 & 0.81 & $(-2.02-1.57)$ & 1.49 & 0.78 & $(-3.61-4.81)$ & 0.60 & 0.59 & $(-1.44-0.82)$ \\
\hline Constant & $0.00^{* * *}$ & 0.00 & $(-0.00-0.00)$ & $0.00^{* * *}$ & 0.00 & $(-0.00-0.00)$ & $0.00^{* * *}$ & 0.00 & $(-0.00-0.00)$ \\
\hline Town Fixed Effect & Yes & & & Yes & & & Yes & & \\
\hline Sample & 606 & & & 329 & & & 606 & & \\
\hline PseudoR2 & 0.35 & & & 0.35 & & & 0.552 & & \\
\hline Log Pseudo Likelihood & -97.2 & & & -105.8 & & & -129.8 & & \\
\hline
\end{tabular}

Note: ${ }^{*}$ refers to $p \leq 0.1{ }^{* *}$ refers to $p \leq 0.01{ }^{* * *}$ refers to $p \leq 0.001{ }^{1}{ }^{1 \cdot}$ All the three variables of subjective assessment have five scales and the groups with least satisfaction in samples are taken as the benchmark. It is worth noting that no participant chose the least satisfaction for life satisfaction and evaluation of local urbanization, so scale 2 is taken as the reference group for the two variables. 


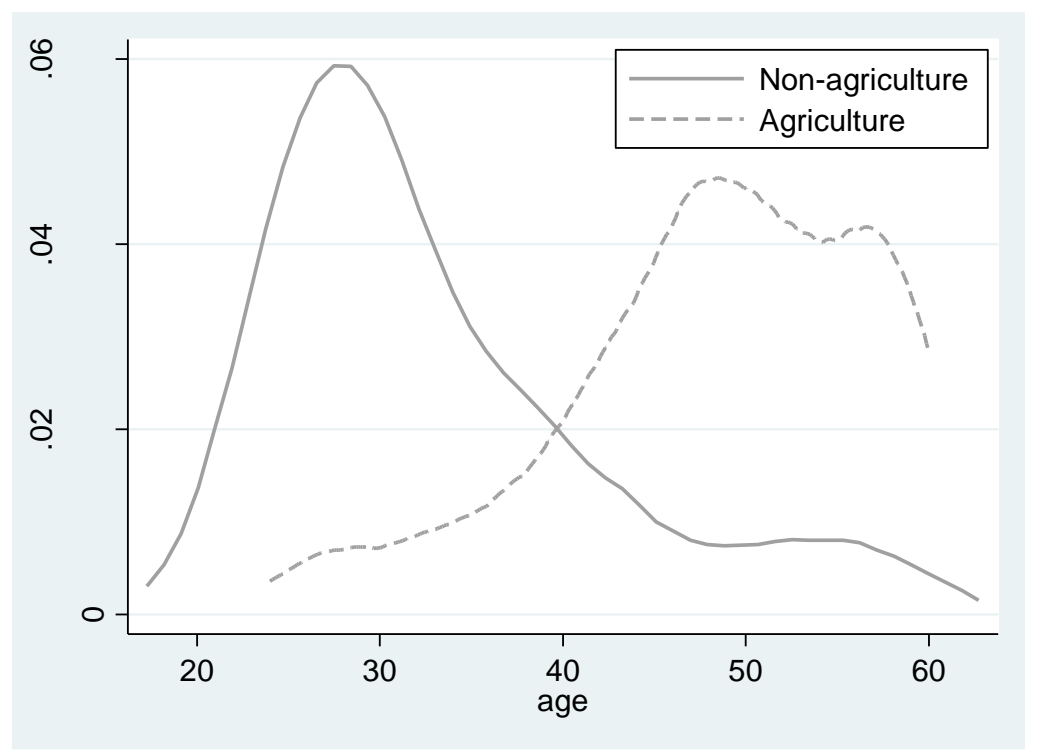

Figure 2. The density of age across the non-agriculture group and agriculture group in Weifang, 2012.

In the first model, the results show that age, marital status, education level, annual income per capita (in logarithm), property ownership in the city, average arable land per capita, annual agricultural income per capita (in logarithm), percentage of residents conducting off-farm jobs, and evaluation of non-agricultural job finding are significantly associated with taking non-agricultural jobs. The participants who are younger $(\mathrm{OR}=0.87, p<0.001)$, have a better education $(\mathrm{OR}=1.25$, $p=0.01)$, have a higher annual income per capita $(\mathrm{OR}=3.34, p<0.001)$, live in a village with a high percentage of residents conducting non-agricultural jobs ( $\mathrm{OR}=1.09, p<0.001)$, and have a high evaluation of non-agricultural job finding $(\mathrm{OR}=5.55, p=0.04)$ are more likely to take non-agricultural work. The participants who have a spouse (OR $=0.97, p<0.001)$ and have more average arable land per capita (OR $=0.52, p<0.001)$ were less likely to take off-farm jobs. Those who have higher agricultural incomes per capita $(\mathrm{OR}=0.98, p=0.06)$ and own property in the city $(\mathrm{OR}=1.01, p=0.01)$ were only slightly more likely to hold non-agricultural jobs.

The results from the second model show that the number of children under seven, education level, annual income per capita (in logarithm), having family members being village officials, land being requisitioned, and living next to an urban area were significantly associated with holding a full-time non-agricultural job. Those who are better educated ( $\mathrm{OR}=1.13, p=0.10)$, have higher annual incomes per capita (in logarithm) $(\mathrm{OR}=3.50, p=0.01)$, and live in a village next to the urban areas $(\mathrm{OR}=1.15, p<0.001)$ were more likely to take full-time non-agricultural jobs. Those who have more children under seven ( $\mathrm{OR}=1.01, p=0.05)$, have family members being village officials $(\mathrm{OR}=1.02$, $p=0.04)$, and have land requisition in a household $(\mathrm{OR}=0.98, p<0.001)$ only had a negligible effect on taking full-time non-agricultural jobs.

The results from the third model show that age, gender, marital status, number of the elderly people in the household, education level, annual income per capita (in logarithm), property ownership in the city, annual agricultural income per capita (in logarithm) and evaluation of local urbanization were significantly associated with work locations. The younger participants $(\mathrm{OR}=0.94, p<0.001)$, better educated participants $(\mathrm{OR}=1.10, p=0.01)$, participants having higher annual income per capita (in logarithm) $(\mathrm{OR}=4.63, p<0.001)$, and those who have higher evaluation of local urbanization $(\mathrm{OR}=1.04, p<0.001$; $\mathrm{OR}=1.07, p<0.001$; $\mathrm{OR}=1.03, p=0.01)$ were more likely to choose non-agricultural jobs lasting over three months outside of their home county in 2012. People having more elderly family members ( $\mathrm{OR}=0.83, p=0.09)$ or having a higher annual agricultural income per capita (OR $=0.63, p<0.001)$ were less likely to take non-agricultural jobs lasting over three months 
outside of Weifang in 2012. Compared to others, those who are males (OR $=1.01, p<0.001)$, who have a spouse (OR $=0.99, p<0.001)$, and own property in the city $(\mathrm{OR}=1.02, p<0.001)$ only had a negligible effect on taking non-agricultural jobs outside of their home county.

The findings of this study partly support our listed hypotheses. The rural residents who are younger were more likely to conduct non-agricultural work out of their county, and single farmers preferred non-agricultural work. The number of the elderly in the household has a negative impact on work location, (that is, non-agricultural work out of their home county). The rural residents with better education or higher annual incomes per capita are more likely to conduct full-time non-agricultural work out of their county. Those who have more average arable land per capita are less likely to conduct non-agricultural work. Those with high annual agricultural incomes per capita are less likely to conduct non-agricultural work out of their county. The rural residents who live next to the urban areas are more likely to work full-time in non-agricultural jobs and those who live in a village with a high percentage of residents working in non-agricultural jobs are more likely to have a non-agricultural job. Males and those who own property in the city are slightly more likely to work in a non-agricultural job outside of their county. Those who have positive perceptions about finding non-agricultural work and have positive evaluation of local urbanization are more likely to have a non-agricultural job.

The following findings, however, do not support the hypotheses. Being a party member and life satisfaction had no significant impact on the likelihood to have a full-time non-agricultural job outside of the county. Having more children under seven in a household and those who have family members being village officials are slightly more likely to have a full-time non-agricultural job. Households with land requisition are slightly less likely to take a full-time non-agricultural job.

\section{Discussion and Conclusions}

In recent decades, China has rapidly urbanized. More and more rural residents are taking non-agricultural jobs, full-time or seasonally, either in a nearby city or moving further away to find non-agricultural jobs, especially in East China [31]. As stated at the beginning of this paper, the patterns of population migration and the process of urbanization are diverse among regions in China. One of the challenges for governments is to promote healthy urbanization. This study is a case study for understanding the factors of non-agricultural job taking by rural residents and its uniqueness during the urbanization process and in the context of the strong influence of Chinese traditional culture in a relatively developed region in China. The findings and policy implications of this study shed lights on promoting healthy urbanization in a developed region of China.

The results of the study show how demographic, socio-economic, land resources, neighborhood effects, and individual perceptions affect decision making related to non-agricultural work. The younger generation is more likely to do non-agricultural work and work outside of their counties, which is consistent with the findings of existing studies [14,16-18]. One possible explanation is that the younger generation is better educated and has more human capital that facilitates the search for non-agricultural jobs outside of their origin counties. Gender plays only a minor role in rural residents' decision to seek non-agricultural work either full time or part-time. However, males are slightly more likely than females to work outside of their home county, which is consistent with many other studies [14,16-18]. A possible explanation is that females take more responsibility to care for children and the elderly members in their families which make them choose jobs close to their villages. Those with a spouse are slightly less likely to have a non-agricultural job compared to those who are single because many of the rural residents had non-agricultural jobs before they got married.

Socio-economic factors are also important for the decision-making process. Education level was found to have a significant positive impact on having full-time non-agricultural work and the workplace. The findings of this study are consistent with those conducted by Scheartz and Zhao $[18,32]$. The increase in the annual income per capital encouraged the rural residents to take full-time non-agricultural work outside of their counties, while higher agricultural incomes reduced the likelihood of seeking non-agricultural work. One possible reason for this contrast is that 
non-agricultural workers earn more money than agricultural workers. The increase in human capital resulting from education enables rural residents to compete for relatively high skilled non-agricultural jobs. Similar to Li and Zahniser, we also showed that an increase in farming income reduces farmers' motivation to migrate [19]. In most rural areas, young farmers are attracted to non-agricultural sectors due to relatively higher earnings. Rural residents, however, are likely to invest in their land if the return to planting is sufficiently high. For example, a large percentage of well-educated farmers use new cultivation techniques to grow vegetables, resulting in high incomes instead of taking non-agricultural jobs in Shouguang city (county-level), called China's "Home of Vegetables". The average yearly income for these households, as estimated by the township officers we interviewed, can reach roughly 80,000 RMB, far more than the earnings of their counterparts in other sectors.

Being a party member did not have a significant impact on decision making, and having family members being village officials only had a slightly positive impact on taking non-agricultural work outside of the county. Owning property in the city has significant and slightly positive impacts on conducting non-agricultural work and work outside of one's home county. One possible reason is that those who conduct non-agricultural work and work outside of Weifang are likely to earn more money to afford properties in the city and they are more likely to take non-agricultural jobs once they own properties in the city. To have properties in the city is an important step in settling down in the city.

The higher arable land per capita reduced the likelihood of taking non-agricultural jobs. On the other hand, land requisition decreases the amount of land controlled by the household and brings some financial compensation, which usually helps rural residents pursue non-agricultural work. The results show that land requisition has a slightly negative impact on full-time non-agricultural work. The possible reason is that the financial compensation for land requisition is high enough that they only need to take part-time jobs or do not even need to seek jobs in non-agricultural sectors.

Neighborhood effects, such as whether there is a high proportion of residents in their villages in non-agricultural sectors, have enormous impacts on people's decision making about non-agricultural work. The adjacency to the urban area makes it more convenient to take a full-time non-agricultural job. These findings reflect the importance of non-economic factors in decision making, including geographical factors and social networks $[5,10,11]$. In addition, the positive perception of local urbanization and opportunities for non-agricultural jobs has a positive effect on rural residents' decision to seek non-agricultural jobs.

A unique finding of this study is that the number of elderly members in the household has a significantly negative impact on the choice of workplace, but no significant impact on the choice of full or part-time non-agricultural work. It implies that family ties are still strongly appreciated in Weifang and that rural residents are willing to care for elderly family members. As the place of origin of the Confucius Culture in ancient China, filial piety still plays an important role in family support on elder care. So people tend to work close to their home villages when they have elderly family members. Similar results were also documented by Giles and Mu, Mullan and Grosjean [20,21]. Even though the governments in Shandong Province put a lot of effort on the improvements in pension, health care, community care, and residential care system in recent years, the rural social system still faces many challenges in providing community and residential care to meet the demands of rural elderly people. The majority of the rural elderly people choose to or have a limited option to age in place in their villages with inadequate social support, which influences migrants' decision making on their workplace location.

The number of children under seven in the household, however, has a slight impact on the decision making on taking full-time non-agricultural work, which is different from the results reported by Li and Zahniser, Mullan and Grosjean [19,21]. One possible explanation is that the GDP per capita in Weifang is relatively high by Chinese standards, even in the rural area. Meanwhile, the family control policy is effectively enforced in the region and most of the families only have one or two children. Many of the children migrate with their parents or are cared for by elderly grandparents, which, therefore, poses no obstacle for non-agricultural work. 
In the Chinese context, land reform, the improvement of agricultural production efficiency, and the industrialization of agriculture in rural areas provide opportunities for many rural residents to shift to non-agricultural sectors. To further understand the implications of the findings, we need to know who are more likely to migrate; whether the rural residents' migration behavior is permanent, for a few years or seasonal; whether they tend to move back and settle down in rural areas after they get married, especially for females; whether the high cost of settling down in urban areas forces them to move back as the size of household increases after being married; how to generate the essential function of rural areas to provide agricultural production as the number of laborers is decreasing if many rural residents intend to migrate to cities for higher income; how cities provide equitable access to social welfare for the migrants; and whether their migration has positive impacts on the sustainable development in both urban and rural areas. This study helps identify these issues and such knowledge is important for policy making in promoting healthy urbanization.

Population aging is another important issue claiming the public and governments' attention. The findings of this study also show the role of elder care in the location choice of taking non-agricultural jobs outside of their home counties. Filial piety is part of the traditional culture in China and family members usually take on the responsibility of providing care for elderly people. The perception of raising children for old age has been popular in rural areas for a long time as social welfare is limited for rural residents. The absence of care services in rural areas loads the burden of elder care on family members and reduces the migration behavior of rural residents to some degree, especially for married females. Policymakers also need to consider how to improve community care services and the social security system to replace the declining family support system.

Some key limitations need to be acknowledged in our study. First, we have no access to those fully urbanized farmers (that is, those whose family members who all live in cities and do not even emerge on the village roster). Second, we only took samples in Weifang which features a highly industrialized prefecture city. So readers need to be cautious to apply our findings in other circumstances. Thirdly, this is a cross-sectional study, which is unable to provide us with information on rural residents' migration behavior from a life course perspective.

To summarize, economic factors play an important role in rural residents' decision making to seek non-agricultural jobs, full-time non-agricultural jobs and work outside of their home county. Non-economic factors such as age, social ties, education, arable land, neighborhood effects, and self-perception are also significant factors in the decision-making process. The findings of this study shed light on the impact of urbanization on rural residents in the developed coastal areas in China. As the population is rapidly aging in China, especially in the rural areas, it is also important to explore how to reform the traditional family support systems during the urbanization process in the future studies. In addition, the study provides knowledge for future policy-making on rural development and management and promoting healthy urbanization.

Author Contributions: Y.C. is responsible for the study design and drafting the manuscript. Y.L. is responsible for data collection and data analysis. M.R. is responsible for drafting the manuscript. L.H. is responsible for the study design and data analysis.

Acknowledgments: The authors acknowledge Shaoxing Li's generosity to share the collected data and the support by the local coordinators from Housing and Construction Bureau of Weifang. The authors also extend thanks to the research participants. This work was supported by Shandong Provincial Natural Science Foundation of China (Grant NO. ZR2016GM24) and Beijing Normal University (2013NT05).

Conflicts of Interest: The authors declare no conflict of interest.

\section{References}

1. Du, Y.; Park, A.; Wang, S. Migration and rural poverty in China. J. Comp. Econ. 2005, 33, 688-709. [CrossRef]

2. Peng, X. China's demographic history and future challenges. Science 2011, 333, 581-587. [CrossRef] [PubMed]

3. Sjastaad, L.A. The costs and returns of human migration. J. Polit. Econ. 1962, 70, 80-93. [CrossRef] 
4. Todaro, M.P. A model of migration and urban unemployment in less-developed countries. Am. Econ. Rev. 1969, 59, 138-148.

5. Massey, D.S.; Arango, J.; Hugo, G.; Kouaouci, A.; Pellagrino, A.; Taylor, J.E. Theories of international migration: A review and appraisal. Popul. Dev. Rev. 1993, 19, 431-466. [CrossRef]

6. Stark, O. The Migration of Labor; Basil Blackwell: Oxford, UK, 1991.

7. Taylor, J.E.; Rozelle, S.; de Brauw, A. Migration and incomes in source communities: A new economics of migration perspective from China. Econ. Dev. Cult. Chang. 2003, 52, 75-101. [CrossRef]

8. Piori, M. Birds of Passage: Migrant Labor and Industrial Societies; Cambridge University Press: New York, NY, USA, 1979.

9. Piotrowski, M.; Tong, Y. Straddling two geographic regions: The impact of place of origin and destination on return migration intentions in China. Popul. Space Place 2013, 19, 329-349. [CrossRef]

10. Curran, S.; Garip, F.; Chung, C.Y.; Tangchonlatip, K. Gendered migrant social capital: Evidence from Thailand. Soc. Forces 2005, 84, 225-255. [CrossRef] [PubMed]

11. Krissman, F. Sin Coyote Ni Patron: Why the 'migration network' fails to explain international migration. Int. Migr. Rev. 2005, 39, 4-44. [CrossRef]

12. Granovetter, M. Economic action and social structure: The problem of embeddedness. Am. J. Sociol. 1985, 91, 481-510. [CrossRef]

13. Korinek, K.; Jampaklay, A.; Entwisle, B. Through thick and thin: Layers of social ties and urban settlement among Thai migrants. Am. Sociol. Rev. 2005, 70, 779-800. [CrossRef]

14. Hare, D. 'Push' versus 'pull' factors in migration outflows and returns: Determinants of migration status and spell duration among China's rural population. J. Dev. Stud. 1999, 35, 45-72. [CrossRef]

15. Ho, S.P. Rural non-agricultural development in post-reform China: Growth, development patterns, and issues. Pac. Aff. 1995, 68, 360-391. [CrossRef]

16. Rozelle, S.; Taylor, J.E.; de Brauw, A. Migration, remittances, and agricultural productivity in China. Am. Econ. Rev. 1999, 89, 287-291. [CrossRef]

17. Zhao, Y. Leaving the countryside: Rural-to-urban migration decision in China. Am. Econ. Rev. 1999, 89, 281-286. [CrossRef]

18. Zhao, Z. Migration, labour market flexibility, and wage determination in China: A review. Dev. Econ. 2005, 43, 285-312. [CrossRef]

19. Li, H.; Zahniser, S. The determinants of temporary rural-to-urban migration in China. Urban Stud. 2002, 39, 2219-2235. [CrossRef]

20. Giles, J.; Mu, R. Elderly parent health and the migration decisions of adult children: Evidence from rural China. Demography 2007, 44, 265-288. [CrossRef] [PubMed]

21. Mullan, K.; Grosjean, P. Land tenure arrangements and rural-urban migration in China. World Dev. 2011, 39, 123-133. [CrossRef]

22. Stewart, Q.J. The development of social physics. Am. J. Phys. 1950, 18, 239-253. [CrossRef]

23. Poot, J.; Alimi, O.; Cameron, M.P.; Maré, D.C. The gravity model of migration: The successful comeback of an ageing superstar in regional science. IZA Discuss. Pap. 2016, 10329. Available online: https:/ / ssrn.com/ abstract $=2864830$ (accessed on 20 May 2018).

24. Borgers, A.; Timmermans, H. Choice model specification, substitution and spatial structural effects. Reg. Sci. Urban Econ. 1987, 17, 29-47. [CrossRef]

25. Cushing, B.J. Accounting for spatial relationships in models of interstate population migration. Ann. Reg. Sci. 1986, 20, 66-73. [CrossRef] [PubMed]

26. Griffith, D.A.; Jones, K. Exploration in the relationship between spatial structure and spatial interaction. Environ. Plan. A 1980, 12, 187-210. [CrossRef]

27. Boots, B.N.; Kanaroglou, P.S. Incorporating the effects of spatial structure in discrete choice models of migration. J. Reg. Sci. 1988, 28, 495-510. [CrossRef] [PubMed]

28. Gao, S.; Cheng, Y. Willingness to relocation of the older people within Beijing. Geogr. Res. 2018, 37, 119-132. (In Chinese)

29. Yu, J.; Rosenberg, M.W.; Cheng, Y. Aging at home and the intent to relocate in Beijing. Prog. Geogr. 2015, 34, 1577-1585. (In Chinese)

30. Li, M.; Sicular, T. Aging of the labor force and technical efficiency in crop production: Evidence from Liaoning province, China. China Agric. Econ. Rev. 2013, 5, 342-359. [CrossRef] 
31. Li, X.; Wang, X. Changes in agricultural land use in China: 1981-2000. Asian Geogr. 2003, 22, 27-42. [CrossRef]

32. Schwartz, A. Interpreting the effect of distance on migration. J. Polit. Econ. 1973, 81, 1153-1169. [CrossRef] (CC BY) license (http:/ / creativecommons.org/licenses/by/4.0/). 